\title{
Facilitating Access to the Role Models of Women in STEM: W-STEM Mobile App
}

\author{
Alicia García-Holgado ${ }^{(\bowtie)}(\mathbb{D})$, Sonia Verdugo-Castro (iD), \\ Mª Cruz Sánchez-Gómez (D), and Francisco J. García-Peñalvo (D) \\ GRIAL Research Group, University of Salamanca, Salamanca, Spain \\ \{aliciagh, soniavercas, mcsago,fgarcia\}@usal.es
}

\begin{abstract}
W-STEM is a research project funded by the European Union through the Erasmus+ program in order to develop concrete actions to modernise the government, management and operation of higher education institutions in Latin America to improve women's access to STEM programs. Among the main objectives of the project, there is the development of a mobile app to be used in attraction campaigns conducted by the Latin American higher education institutions involved in the project. Specifically, the app aims to facilitate access to the role models of women in areas related to science, technology, engineering and mathematics. The main content inside the app will be a set of video interviews with women from different ages, culturat backgrounds, profiles, sharing their experiences about their careers, occupation and future plans. This work aims to describe the prototype of the mobile app and the exploratory study conducted with a group of students from secondary education to know their perceptions and opinions about the proposed app and the video interviews.
\end{abstract}

Keywords: Gender gap - Women visibility $\cdot$ STEM $\cdot$ Mobile app ·

Acceptance $\cdot$ User perception Secondary school $\cdot$ Students

\section{Introduction}

Women are one of the least represented groups in science, technology, engineering and mathematics (STEM) areas. The underrepresentation of women in these areas, for reasons unrelated to their talent or preferences, represents significant economic losses for modern societies [1]. In general, the greater participation of women is related to economic growth, the promotion of human development, the strengthening of the competitiveness of the region and the increment of productivity [2]. According to the European Commission's strategy [3], increasing women's participation in the technology sector will boost the economy and enable their full participation in society. In particular, according to the report "Women in the Digital Age", the incorporation of more women into digital jobs would benefit Europe's Gross Domestic Product (GDP) by up to 16 billion euros per year [4].

Improving the recruitment, retention and training of the next generation of STEM professionals remains an area of political priority and concern [5]. There are initiatives across the world promoted by governments, companies, associations, working on reducing the gender gap in STEM [6]. For example, international associations such as 
ACM or IEEE have projects to improve the representation of women in the scientific and technological field, ACM-W (https://women.acm.org) and IEEE Women in Engineering (https://goo.gl/p9xgyH).

The European Advisory Committee on Equal Opportunities for Women and Men [7] identifies the promotion of non-stereotypical education, training and career choices as one of the actions to tackle gender segregation labour-market. Among the suggested recommendations, they propose to ensure that educational curricula at all levels eliminate gender stereotypes, as well as the need to perform extensive reviews of current educational material with a view to gender equality. Also, the OECD emphasises in "reviewing and where necessary, adapting school and early childhood education curricula, teaching and school practices to eliminate gender discrimination and stereotyping" [8]. Equity in the development of STEM competencies must look beyond the educational offer or the promotion of professions focused on science and technology, taking into account the need to empower young women before choosing a university career [9].

Several studies analyse gender bias and stereotypes in educational resources [10]. Kerkhoven et al. [11] analysed online science education resources provided through the Scientix and OERcommons websites; they found the ratio of women depicted with a science profession was 25\%. Parkin and Mackenzie [12] presents a tool to measure the gender bias in textbooks; the tool is tested in science textbooks used in the secondary education in the UK concluding that they have a strong bias towards males. López Navajas [13] analyses the presence of women in the textbooks used in the Spanish secondary education; she found that only $12.7 \%$ of all the characters mentioned in the textbooks are women, and these only appear in the textbooks on $7.6 \%$ of the cases.

According to Smith [5] encouraging young girls to imagine employment in STEM areas is an important step towards improving their representation. However, women in STEM are made invisible by society not only in educational material but also in the media [14]. In the case of Latin America, the low representation of women in scientific and technological areas does not allow for the production of reference models for their incursion into these areas [9].

The revision and modification of the school textbooks in the different countries, suppose a huge investment of the publishers and also from families and schools who have to replace the existing textbooks. Although this process must be implemented to eliminate gender discrimination and stereotyping, it requires time and investment. Moreover, the school textbooks and the educational system depends on the national governments, so each country manages different times to achieve this type of objectives as a measure to avoid the gender gap in STEM. For this reason, other measures have to be implemented to reduce gender bias and stereotyping at schools and encourage young girls to select STEM careers.

The W-STEM project funded by the European Union through the Erasmus+ program arises in order to develop concrete actions to modernise the government, management and operation of higher education institutions in Latin America to improve women's access to STEM programs $[15,16]$. Among their goals is the promotion of STEM studies vocation and choice in girls and young women in secondary schools. The ten Latin American higher education institutions involved in the project will define a gender equality action plan focused on three processes: attraction, access and 
guidance/retention. The actions associated with secondary schools are related to the attraction processes. The ten Latin American higher education institutions (Table 1) will define and implement attraction campaigns with the support of two software tools. First, the profiling tool based on [17] to identify prospective students, successful graduates and current students, with key aptitudes correlated to STEM disciplines/ professions. On the other hand, a mobile app to share women in STEM stories as a way to facilitate reference models to young girls.

Table 1. W-STEM project details.

\begin{tabular}{l|l}
\hline $\begin{array}{l}\text { Heading } \\
\text { level }\end{array}$ & Example \\
\hline Title & Building the future of Latin America: engaging women into STEM \\
\hline Acronym & W-STEM \\
Funding & European Union \\
\hline Call & $\begin{array}{l}\text { ERASMUS+ Capacity-building in Higher Education Call for proposals } \\
\text { EAC/A05/2017 }\end{array}$ \\
\hline Reference & 598923-EPP-1-2018-1-EN-EPPKA2-CBHE-JP \\
\hline Coordinator & P1. University of Salamanca - USAL (Spain) \\
\hline Partners & $\begin{array}{l}\text { P2. Universidad del Norte - UNINORTE (Colombia) } \\
\text { P3. Oulu University - OULU (Finland) } \\
\text { P4. Politecnico di Torino - POLITO (Italy) } \\
\text { P5. Technological University Dublin - TUD (Ireland) } \\
\text { P6. Nothern Regional College - NRC (United Kingdom) } \\
\text { P7. Tecnológico de Monterrey - ITESM (Mexico) } \\
\text { P8. University of Guadalajara - UG (Mexico) } \\
\text { P9. Federico Santa María Technical University - UTSM (Chile) } \\
\text { P10. Pontifical Catholic University of Valparaíso - PUCV (Chile) } \\
\text { P11. Technological University of Bolívar - UTB (Colombia) } \\
\text { P12. Costa Rica Institute of Technology - ITCR (Costa Rica) } \\
\text { P13. University of Costa Rica - UCR (Costa Rica) } \\
\text { P14. Private Technical University of Loja - UTPL (Ecuador) } \\
\text { P15. Technical University of the North - UTN (Ecuador) }\end{array}$ \\
\hline $\begin{array}{l}\text { 862.268 } € \\
\text { 3 years. 01/15/2019-01/14/2022 } \\
\text { https://wstemproject.eu }\end{array}$ \\
\hline Budget
\end{tabular}

This work describes the prototype of the mobile app and the exploratory study conducted with a group of students from secondary education to know their perceptions and opinions about the prototype and the contents that will be shared through the app in the attraction campaigns.

The work is set out as follow. The second section describes other mobile apps to give visibility to women in STEM. The third section describes the prototype of the W-STEM mobile app. The fourth and fifth sections describe the students' perception 
and opinions of the prototype. The last section concludes the work with its more significant contributions.

\section{Related Mobile Apps}

A search in Apple Store and Play Store was conducted to analyse other mobile apps focused on women in STEM. There are four apps available for iOS and Android related to women in STEM:

- "Women in STEM and Medicine": a free mobile app available for iOS and Android with 100 women who contribute to STEM and medicine in the United States forward. The app is available only in English.

- "Women Who Changed the World": a non-free mobile app available for iOS and Android that introduces several historical women - artists, scientist, civil rights activists, etc. - through illustrations. The app is available in different languages, including Spanish and English.

- "Femmes de Science": free mobile app available for iOS and Android with information about the women professors at the École polytechnique fédérale de Lausanne (Switzerland). Each woman professor share information about her scientific field through a short film.

- "Girls can do I.T.": free mobile app available for iOS to learn more about career opportunities in computer science and information technology. Among the information provided, there are 50 profiles of women in tech.

Although mobile apps are continually appearing, no similar applications to the one proposed in the W-STEM project were found when this search was conducted (01/2020).

\section{Prototype of the W-STEM App}

The purpose of the W-STEM mobile app is to give visibility to women in STEM careers, not only women of a very high level in STEM, but also young women with different profiles - last year students, PhD students, young researchers, developers, etc. The app will be used as a tool in schools and high schools all over Latin America to show young women in STEM, since the books and materials used in the classroom only show examples of men. It is intended to give young people ideas about what it means or why to study STEM careers.

The app handles two types of content: articles and profiles of women in STEM. The articles are used to share news, events or information related to women in science, technology, engineering or mathematics. They consist of a title and a body with text, links and at least one pictures (Fig. 1). Although articles are not the main objective of the W-STEM mobile app, it provides updated information that can be used to engage young girls. 

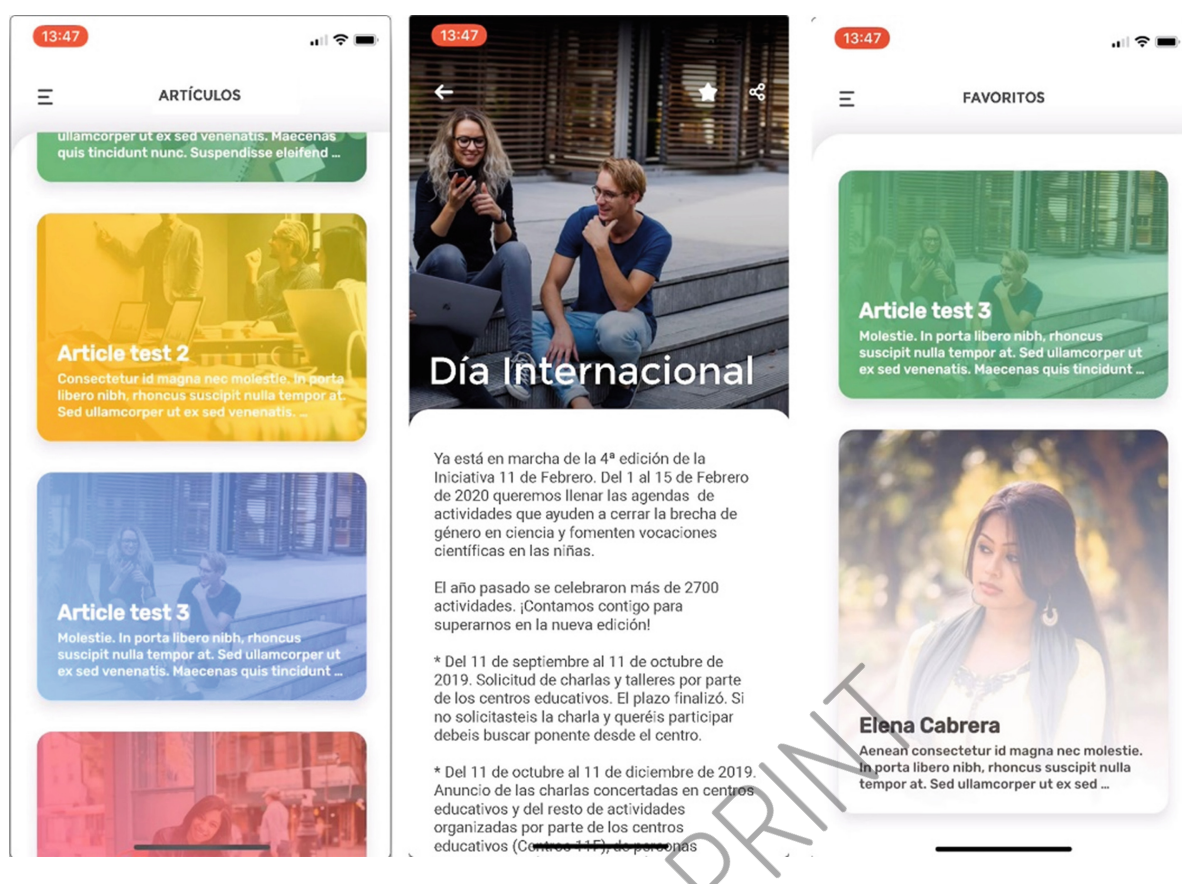

Fig. 1. Screenshots in Spanish of the prototype: article list, article example and favourites.

Regarding the profiles of women in STEM (Fig. 2), each profile is composed of a 2-3 min interview and a set of metadata: the country, the field of work/study, a brief description and a set of links to social profiles. The team from the Tecnologico de Monterrey (Mexico) has defined a protocol to collect, edit and translate the interviews. Each institution involved in the project have to collect 25 women's profiles, so a total of 375 videos will be available through the mobile app. Moreover, video interviews to world-renowned scientists are eonducted in the L'Oreal UNESCO awards ceremonies during the three years of the project with the support of the Columbus Association and UNESCO.

The application is organized into four main screens. The start screen shows featured articles and women's profiles (Fig. 2). A menu in the top of the screen allows access to the other screens of the app: a list of articles, a list of women's profiles and the contents marked as favourites.

The W-STEM mobile app should be available for Android (to be used in devices with different prices) and iOS. The development of native mobile apps supposes a double effort and increases the maintenance cost. For this reason, the prototype was developed using Flutter [18], a Google software development kit (SDK) that allows native development for iOS and Android, based on a unique code.

The main problem of the prototype is the storage and streaming video. Although videos long 2-3 min, they are recorded in high quality with an average of 100$200 \mathrm{MB}$ after the editing process. Videos can be available through a cloud storage service such as Amazon S3 or Firebase Storage, but this solution involves a store and 


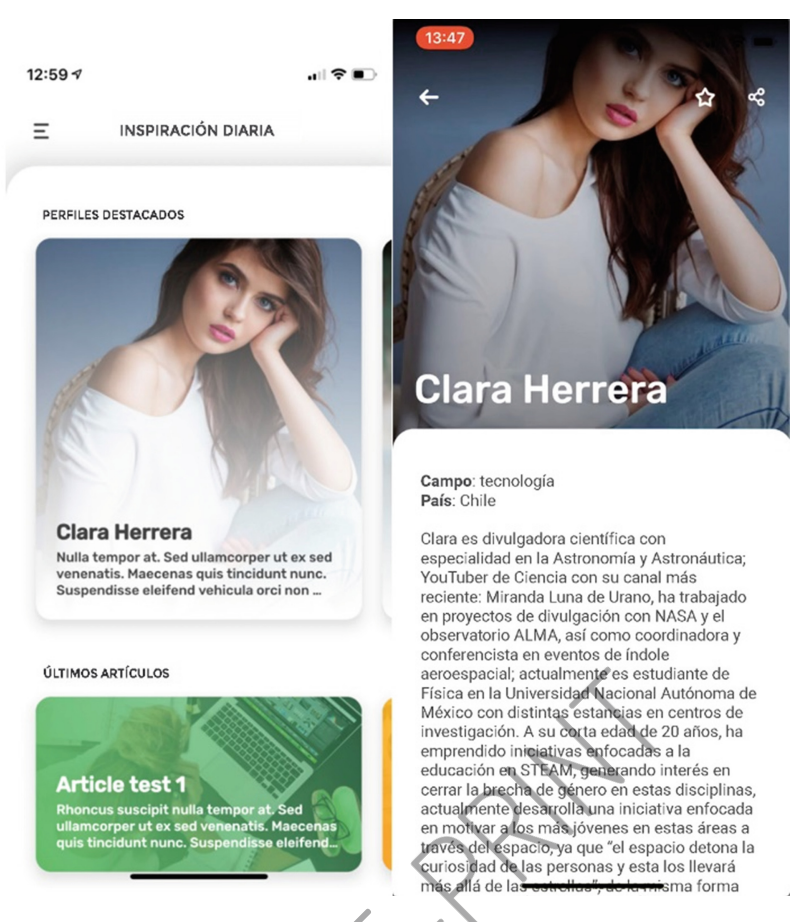

Fig. 2. Screenshots in Spanish of the prototype: start screen and women profile example.

streaming cost according to the files size and the number of users of the app. To reduce maintenance cost and allow the free availability of the final version of the app in the Play Store and Apple Store, the video storage and streaming is based on YouTube.

\section{Exploratory Study}

\subsection{Participants}

The exploratory study was conducted in the IES Venancio Blanco, a public high school in Salamanca (Spain). In particular, the questionnaire was shared among all students in the first and second year of Spanish Baccalaureate, the post-16 stage of education in Spain. The population was composed of a total of eight groups of students from two baccalaureate branches - science and technology, and humanities and social science.

\subsection{Instrument}

The questionnaire was developed ad-hoc to collect qualitative data about the perception and opinions of the students. The instrument was divided into three sections: context, contents of the app, and usability and usefulness of the app. The first section is a set of questions to contextualise the answers. This section has the following demographic questions: 
1. Age (Age ranges).

2. Country.

3. The country where you were born.

4. The country where your parent or guardian was born.

5. The country where your mother or guardian was born.

6. Gender (male, female, not mentioned above, no answer).

Later, a set of questions to find out what the student uses his mobile phone for:

7. Do you have a smartphone? (Yes/No)

8. Select how many apps on your mobile have been downloaded (those that did not come in the mobile when you bought it)

9. Have you ever paid for a mobile app? (Yes/No)

10. If yes, what type of mobile app? (Games, social networks, photography, education, music, sport, etc.)

The last part of the contextualization section has a set of questions to analyse the need for information related to support their decisions after finishing high school:

11. Are you looking for information on the Internet about what you would like to study after high school? (Yes/No)

12. If yes, why on the Internet? What kind of information are you looking for?

13. If not, what are your reasons for not seeking information?

14. Do you know women who work in science, technology, engineering or mathematics? What is your opinion of them?

The next section is focused on getting feedback about the video interviews that will be available through the app. A demo video was recorded and edited. The person interviewed is a 25-year-old woman, a computer engineer who is studying for a doctorate at a Spanish university. The video is followed by two questions:

15. What do you like the most about the video?

16. What do you like least or not like about the video?

Finally, regarding the usability and usefulness of the app, a video showing the prototype and set of screenshots in Spanish are provided at the beginning of this section (Fig. 1, Fig. 2 and other two screenshots):

17. When you watch the start screen, can you identify at a glance what the most relevant content offered was? Can you describe it?

18. Can you see on the screens, how to navigate through the different screens? Is it easily distinguishable?

19. After a first look, is it clear to you what the purpose of the app is? What contents and functions does it offer? Can you list them?

20. Do you think the contents and tools that will be offered in this app are useful for you? Why?

21. What is your opinion about the design of the app? Design means the colours, how the profiles are shown, the menu, how you navigate from one content to another, etc. 
22. What caught your attention the most about the usefulness of the app from a positive point of view?

23. What caught your attention the most about the usefulness of the app from a negative point of view?

24. What should we add in the app for you to use?

25. What should we remove from the app for you to use?

The definition of the instrument was conducted in three phases. First, the people involved in the definition of the app defined a draft of questions. Second, two experts in qualitative analysis review the questionnaire and provided feedback. The updated version of the instrument was shared with two teachers from secondary education who completed it to ensure that it was understood properly by the students.

\subsection{Data Collection}

The prototype is not available to be tested in mobile phones without supervision. Moreover, due to the legal issues to organize a focus group with students, the authors decided to use a qualitative approach based on a questionnaire. Besides, the questionnaire has made it possible to cover a larger population.

The instrument was implemented using a customized version of LimeSurvey, an Open Source online statistical survey web application. The instrument was applied in Spanish.

Regarding the data collection, the questionnaire was shared with the support of a teacher from the high school. He shared the link to the questionnaire with their students during his class sessions. The link was available one month. During that period, two reminders were shared by the teacher to request more answers.

\subsection{Sample}

The questionnaire was answered for 26 students, 9 are male (34.61\%), 16 are female $(61.54 \%)$, and 1 prefer not to answer $(3.85 \%)$. Regarding the age, 3 students are 13-15 years, 22 are 16-18 years, and 1 is 19-21 years. There are two students who born outside Spain (Morocco and Venezuela) and other three students with a migrant background (one of the parents is foreign).

Regarding the use of mobile apps, only three students have paid-for apps in the categories of games, photography and education. All of them has some apps installed in their phones, although only four students have more than 31 apps.

\section{Results}

\subsection{Contextualization}

The main objective of the mobile app is to facilitate reference models in STEM to young girls, although it could be useful to provide information about different careers. In this sense, most of the participants $(80.77 \%)$ look for information on the Internet about what study after high school. Mainly, they seek information to decide which 
career study, to know the job opportunities that a specific career may offer and to get more details about universities, prices requirements. Noteworthy the following answer:

"I look for experiences of people who have been in my situation to know what they did and to guide me a little. Honestly, it hasn't helped me at all" (woman, 16-18 years)

Regarding the information that they have about women who work in STEM, $38.46 \%$ does not know women in those areas. Those who do know women in STEM relate them with the following terms: smart, confident, commitment, perseverance, hardworking, self-reliant and professionals. In the words of some of the participants:

"I think they are there by their own efforts and merits, therefore they deserve it like anyone else" (woman, 16-18 years)

"no opinions, they're just doing their job like a normal person" (man, 16-18 years)

"It seems to me that as long as you like what you do, you are welcome, with motivation everything is done well, whether you are a woman or a man." (woman, 16-18 years)

"I think it does a great job" (man, 16-18 years)

\subsection{Contents of the App}

The mobile app will have video interviews of women in STEM with different characteristics and profiles. Although it is not possibly getting an evaluation of all the videos that will be available through the app, the example used shows the main elements of those videos.

In particular, $73.98 \%$ of the participants answer the questions related to the video interview. The positive comments are related to the way the interviewee express herself and her answer to the questions. The most frequently repeated terms are honesty and clearness. Other positive comments of the participants:

"That a woman studies things which people have usually classified as "men's studies" and that she is so empowered" (man, $16-18$ years)

"That she has specialized in what she really liked as a child and had a vocation to start in something that everyone says is bad or gives a lot of vice." (woman, 16-18 years)

"That she's come to study something she's wanted since childhood" (woman, 16-18 years)

Regarding the question about things that least like about the video, only 5 students answered these questions (19.23\%). The main comments are related to technical issues:

"The background, the stereo noise and that at the beginning of each question after the pause the camera moves." (man, 16-18 years)

"The place where the interview is given and not asked the questions on the video. Transitions make some of the interest in the video go away." (man, 16-18 years)

\subsection{The Interface}

Regarding the usability and usefulness of the app, only 6 students provided some information (26.92\%). All users identify the purpose of the app, the contents available 
and the way to navigate through the different screens. There are 4 students that consider that the contents offered in the app are useful for them:

"They are useful for anyone, it just depends on that person's interest" (man, 16-18 years)

"If they can help your way of life" (woman, 16-18 years)

"I really don't think so, because it seems to me that it's more aimed at women who want to go into science careers and not like me who really knows what career I want and what branch it's from" (woman, 16-18 years)

All comments about the design are positive: original, well organized, good, right colours, minimal.

\section{Conclusions}

Governments and international organisms highlight the need for eliminating gender discrimination and stereotyping from the educational systems. The W-STEM project has among their goals the promotion of STEM studies vocation and choice in girls and young women in secondary schools. To achieve this objective, a mobile app will be developed to share women in STEM stories as a way to facilitate reference models to young girls.

The review conducted in the leading app stores shows that there are no other apps with the same objective, in which real women from different ages, cultural backgrounds and, in general, different profiles, share their own life and working experience in STEM.

On the other hand, the study conducted in a high school in Spain has provided useful information to improve the development of the contents available in the WSTEM mobile app. No criticism has been received of the questions asked; in fact, the comments highlight the content of the interview itself as something to be valued. The comments on elements to be improved have focused on the technical aspects, which allow to improve the protocol for recording and editing the interviews that each partner has to carry out.

However, the comments related to the usability and usefulness of the app are not enough. It is necessary to conduct other study with real users and a functional version of the mobile app to get more information about these aspects.

Acknowledgments. This research was partially supported by the Spanish Ministry of Science, Innovation and Universities under a FPU fellowship (FPU017/01252).

This work has been possible with the support of the Erasmus+ Programme of the European Union in its Key Action 2 "Capacity-building in Higher Education". Project W-STEM "Building the future of Latin America: engaging women into STEM" (Reference number 598923-EPP-12018-1-ES-EPPKA2-CBHE-JP). The content of this publication does not reflect the official opinion of the European Union. Responsibility for the information and views expressed in the publication lies entirely with the authors.

Also, this work has been partially funded by the Spanish Government Ministry of Economy and Competitiveness throughout the DEFINES project (Ref. TIN2016-80172-R). 


\section{References}

1. Gomez Soler, S.C., Abadía Alvarado, L.K., Bernal Nisperuza, G.L.: Women in STEM: does college boost their performance? High. Educ. 1-18 (2019). https://doi.org/10.1007/s10734019-00441-0

2. UN Women: Facts and Figures: Economic Empowerment (2018)

3. European Commission: Women in Digital (2019)

4. Quirós, C.T., Morales, E.G., Pastor, R.R., Carmona, A.F., Ibáñez, M.S., Herrera, U.M.: Women in the Digital Age. Publications Office of the European Union, Brussels (2018)

5. Smith, E.: Women into science and engineering? Gendered participation in higher education STEM subjects. Br. Educ. Res. J. 37, 993-1014 (2011)

6. González, C.S., et al.: Gender and engineering: developing actions to encourage women in tech. In: 2018 IEEE Global Engineering Education Conference (EDUCON), 17-20 April 2018, Santa Cruz de Tenerife, Canary Islands, Spain, pp. 2082-2087. IEEE, USA (2018)

7. Advisory Committee on Equal Opportunities for Women and Men: Opinion on how to overcome occupational segregation. European Commission (2015)

8. OECD: 2013 OECD Recommendation of the Council on Gender Equality in Education, Employment and Entrepreneurship. OECD Publishing, Paris, France (2017)

9. Arredondo Trapero, F.G., Vázquez Parra, J.C., Velázquez Sằnchez, L.M.: STEM y Brecha de Género en Latinoamérica. Revista de El Colegio de San Luis 9, 137-158 (2019)

10. Makarova, E., Aeschlimann, B., Herzog, W.: The gender gap in STEM fields: the impact of the gender stereotype of math and science on secondary students' career aspirations. Front. Educ. 4, 60 (2019)

11. Kerkhoven, A.H., Russo, P., Land-Zandstra, A.M., Saxena, A., Rodenburg, F.J.: Gender stereotypes in science education resources: a visual content analysis. PLoS One 11, e0165037 (2016)

12. Parkin, C., Mackenzie, S.: Is there gender bias in key stage 3 science textbooks?: Content analysis using the gender bias 14 (GB14) measurement tool. Adv. J. Prof. Pract. 1, 23-40 (2017)

13. López Navajas, A.: Las mujeres que nos faltan. Análisis de la ausencia de las mujeres en los manuales escolares. Universitat de València, Valencia, Spain (2015)

14. González, D., Mateu, A., Pons, E., Domínguez, M.: Women scientists as decor: the image of scientists in Spanish press pictures. Sci. Commun. 39, 535-547 (2017)

15. García-Holgado, A., Camacho Díaz, A., García-Peñalvo, F.J.: Engaging women into STEM in Latin America: W-STEM project. In: Conde-González, M.Á., Rodríguez Sedano, F.J., Fernández Llamas, C., García-Peñalvo, F.J. (eds.) Proceedings of the 7th International Conference on Technological Ecosystems for Enhancing Multiculturality (TEEM 2019), León, Spain, 16-18 October 2019, pp. 232-239. ACM, New York (2019)

16. García-Peñalvo, F.J.: Women and STEM disciplines in Latin America: The W-STEM European Project. J. Inf. Technol. Res. 12, v-viii (2019)

17. Ballatore, M.G., et al.: Increasing gender diversity in STEM: A tool for raising awareness of the engineering profession. In: Conde-González, M.Á., Rodríguez Sedano, F.J., Fernández Llamas, C., García-Peñalvo, F.J. (eds.) Proceedings of the 7th International Conference on Technological Ecosystems for Enhancing Multiculturality (TEEM 2019), León, Spain, 1618 October 2019, pp. 216-222. ACM, New York (2019)

18. https://flutter.dev/ 